\title{
Evaluation of the use high resolution satellite Imagery to map slope instability in a tropical environment: St. Thomas, Jamaica
}

\author{
Servel Miller ${ }^{\mathrm{a}}$, Małgorzata Leszczyńska ${ }^{\mathrm{b}}$ \\ ${ }^{a}$ University of Chester, Department of Geography and Development Studies, Parkgate Road, Chester, Cheshire CHI 4BJ, UK \\ ${ }^{b}$ University of Warmia and Mazury in Olsztyn, Faculty Geodesy and Land Management, Oczapowskiego 2, 10-957 Olsztyn, Poland
}

\begin{abstract}
Landslides are a major natural hazard in Jamaica, and have resulted in loss of life, major economic losses, social disruption and damage to public and private properties. There is a need to delineate areas that are prone to slope instability in order to mitigate their effects. The first and most important stage for the creation of a landslide risk maps is the collection of accurate landslide data in a timely manner. However the type of terrain makes landslide mapping particularly difficult. Aerial Photographs have proven to be an effective way of mapping landslides but acquiring new photographs to map recent landslides is very expensive. High resolution satellite imagery were evaluated for their effectiveness in delineating landslides. The landslides on a whole had no distinctive spectral property; hence no one classification technique could be used to identify them. This research developed integrative methods utilising a combination of: edge enhancement to delineate the scarps area; Wetness Index to identify back titling blocks and debris flow lobes where moisture is higher; shape classification (to distinguish from e.g. ground cleared for agriculture); and slope curvature to map scarps. The information from the image classification was combined in a GIS and automated to determine the probability of the presence and or absence of a landslides. Data derived was validated against detailed field mapping at a scale of 1:5000. For more recent landslides, the modelling proved to be effective, accurately identifying $91 \%$ of the landslide both in terms of the location and extent. For the older landslides Pre 2000) the mapping was less effective, with misclassification as high as $24 \%$ particularly for smaller landslides. However, the use of these imagery does have great potential as they prove useful for mapping new landslides quickly and efficiently after landslide disaster and are much cheaper and quicker to acquire.
\end{abstract}

Keywords: natural hazard; landslide risk maps; landslide data; Geographical Information System.

\section{Background}

Jamaica is an island located in the Caribbean Sea (see Fig. 1) which is highly prone to slope instability. The country experience a tropical climate, with an average temperature of around 22 degree Celsius. The island is dominated by highly vegetated mountains reaching elevations of over 2200 metres (see Fig. 2) and coastal plains dominantly used for agricultural purposes. Jamaica's topography is characterized by rugged steep hills and mountains covered by deeply weathered soils, that make the slopes particularly prone to land instability. Mass movements are a major natural hazard in Jamaica, and have resulted in loss of life, major economic losses, social disruption and damage major infrastructure (see Fig. 3) and public and private properties (see Fig. 4). Jamaica is located in the track of the north Atlantic hurricanes passing through the Caribbean [9]. The island of Jamaica lies in the hurricane belt which bring much rainfall, which compounds the slope instability problem [3]. The incidence of landslides increases particularly in those areas which have a high annual rainfall for example the Blue Mountains located in the eastern end of the island. The damages caused by landslides are of economic, societal and environmental concern. Although it is difficult to prevent most of these landslides from occurring, we can certainly mitigate their impact. There is a need to delineate areas that are prone to slope instability in order to mitigate their effects. The first and most important stage for the creation of a landslide risk maps is the collection of accurate landslide data in a timely manner. However, the ruggedness of the terrain, high vegetation cover and general poor accessibility makes landslide mapping particularly difficult. Aerial Photographs and field geomorphic mapping have proven to be an effective way of mapping landslides but acquiring but can be time consuming, labour intensive and expensive. The Government of Jamaica

Corresponding author: Małgorzata Leszczyńska. E-mail address: malgorzata.leszczynska@uwm.edu.pl

http://dx.doi.org/10.3846/enviro.2014.229

(C) 2014 The Authors. Published by VGTU Press. This is an open-access article distributed under the terms of the Creative Commons Attribution License, which permits unrestricted use, distribution, and reproduction in any medium, provided the original author and source are credited. 
has country covered by High resolution IKONOS Optical satellite imagery, that are freely available. These imagery were evaluated for their effectiveness in delineating landslides.

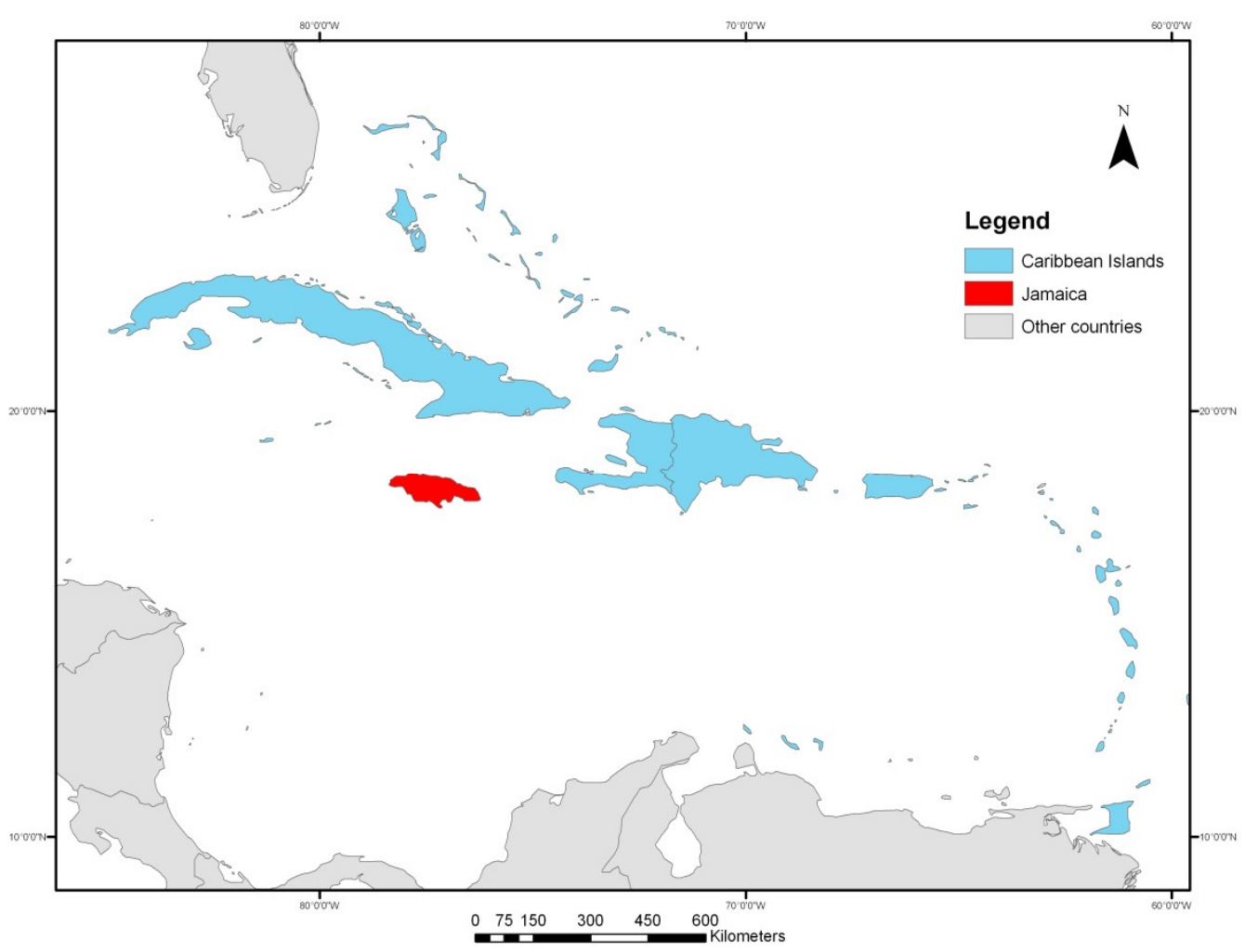

Fig. 1. Location of Jamaica

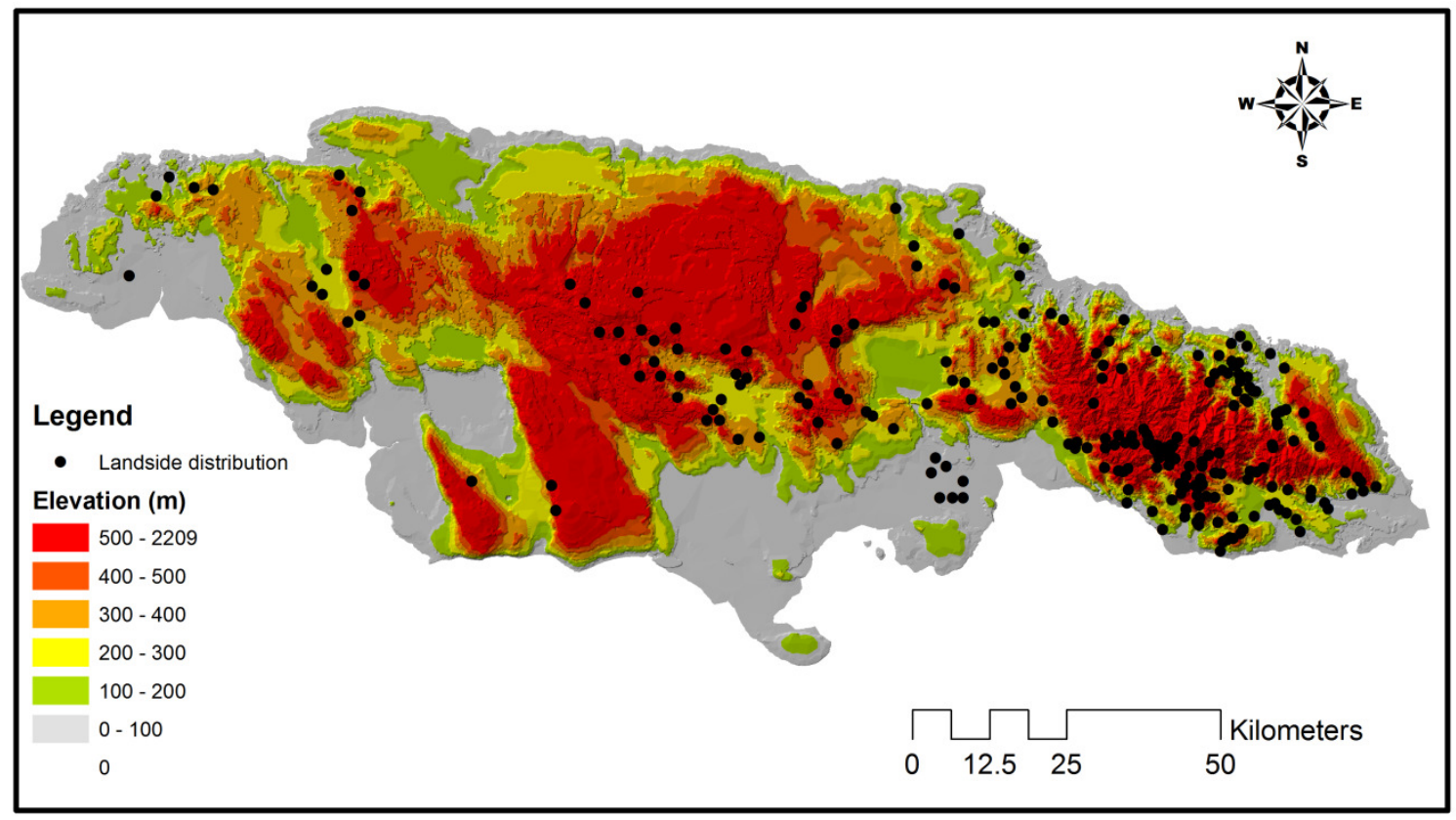

Fig. 2. Elevation Map of Jamaica with known landslide distribution 


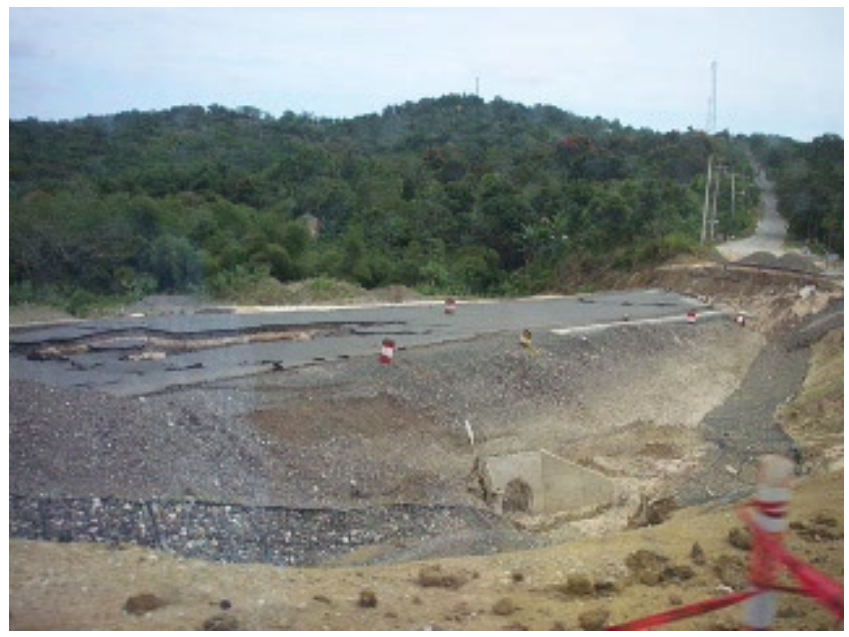

Fig. 3. Damage to road network cause by landslides

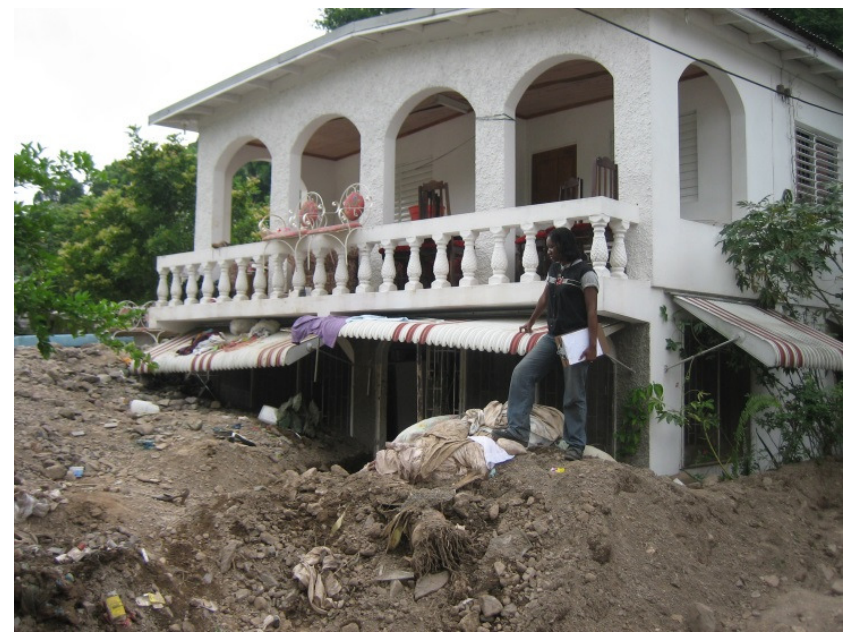

Fig. 4. Partially buried building in landslide debris

\subsection{IKONOS Imagery}

In 2001, the Government of Jamaica acquired IKONOS satellite imagery coverage for the entire country. IKONOS imagery are both Panchromatic and Multi-Spectral. The panchromatic imagery is $1 \mathrm{~m}$ (Pan sharpened) spatial resolution. Multispectral image with spectral range from $0.445-0.516 \mu \mathrm{m}$, is at $4 \mathrm{~m}$ Spatial resolution (see Table 1). The Multispectral imagery is separated in three visible bands (blue, green and red) and near infrared [10].

Table 1. Spectral Resolution of IKONOS imagery

\begin{tabular}{l|l|l}
\hline Band & 1-m PAN & $4-\mathrm{m} \mathrm{MS} \mathrm{\&} \mathrm{1-m} \mathrm{PS}$ \\
\hline 1 (Blue) & $0.45-0.90 \mu \mathrm{m}$ & $0.445-0.516 \mu \mathrm{m}$ \\
2 (Green) & $*$ & $0.506-0.595 \mu \mathrm{m}$ \\
3 (Red) & $*$ & $0.632-0.698 \mu \mathrm{m}$ \\
4 (Near IR) & $*$ & $0.757-0.853 \mu \mathrm{m}$
\end{tabular}

\section{Methodology}

Landslides have been successfully and effectively mapped using geomorphic method and aerial Photogrammetry in Jamaica [18], [6]. However, whilst successfully, they can be very time consuming and labour intensive. The rationale for this research was to explore the use of available IKONOS high resolution satellite image, combined with available 1:10000 Scale DEM to map landslide in a tropical area. In such terrain, landslides are highly vegetated and not readily identifiable. This research is focused mainly on evaluating the potential of these techniques and to explore their transferability to other areas of Jamaica.

\subsection{Mapping of Landslides: Key features}

In Jamaica, landslides appear in a diverse manner ranging from debris and mud flows to translational landslides and rotational slides [18], [19]. The debris and mud flows typical occur after periods of prolonged rainfall. Invariable, these are reactivation of existing (relict) larger Rotational and Translation slides. Debris flows when they occur can be easily map due to readily visible bare scarps (see Fig. 5). Although, after a few years they become vegetated and very difficult to identify. The same applies to rotational and translations landslides which forms distinct 'back scarp/s' (see Fig. 5) which are easily recognises when they occur but can become vegetated after a few years. The challenge therefore is to map these slides, which still poses a threat to development, lives and livelihood if not identified. 


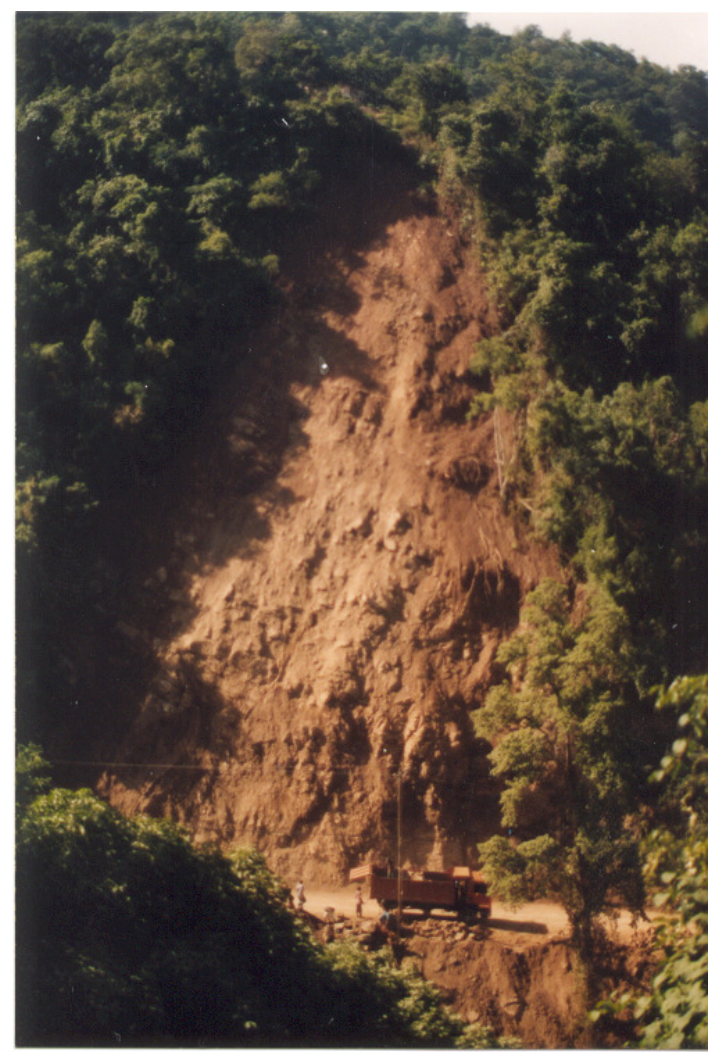

Fig. 5. Landslide with its distinct flow path and bare ground that makes it very recognisable

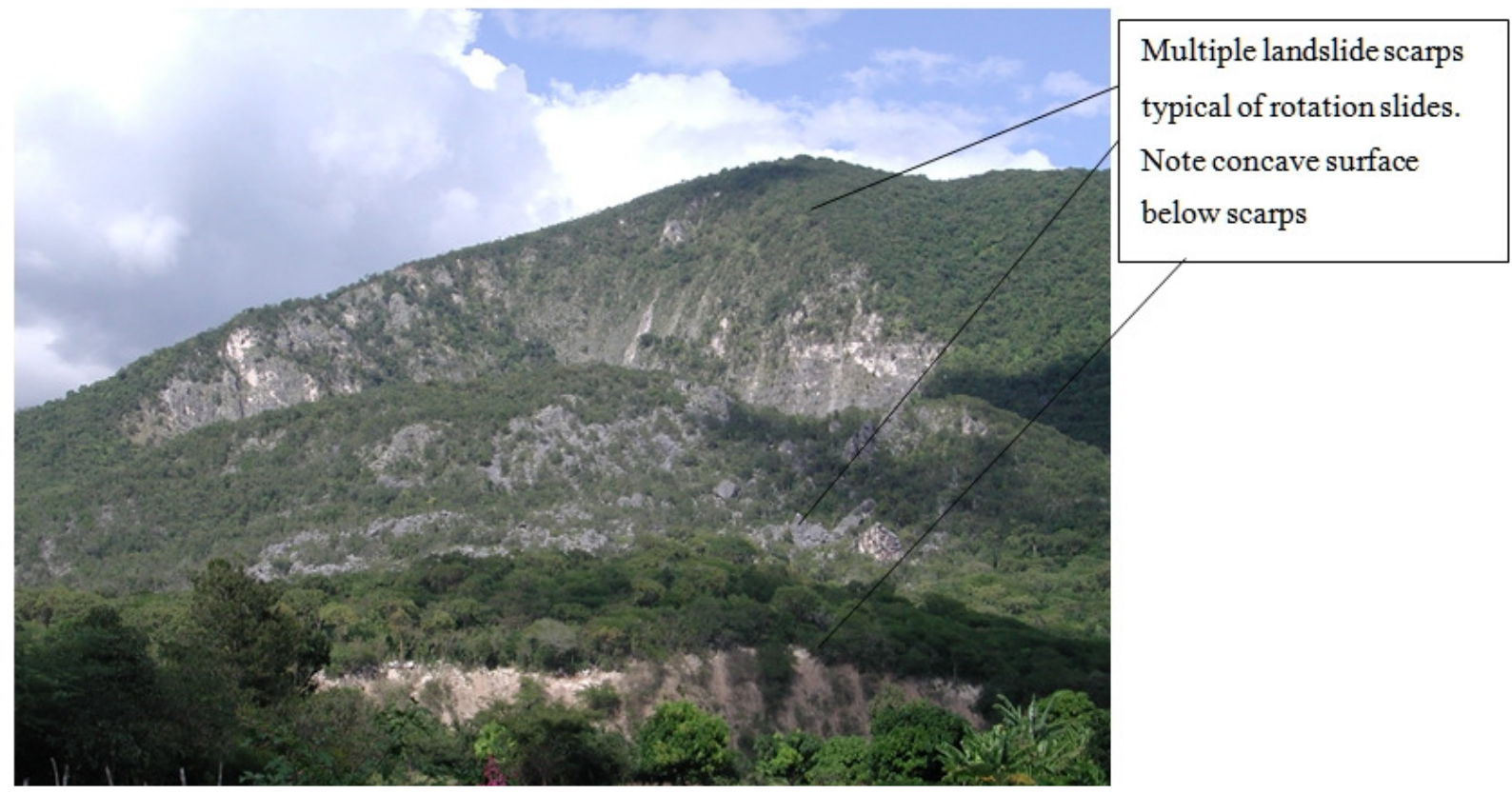

Fig. 6. Multiple scarps of rotational landslides that maybe mapped

\subsection{Remote sensing and the Mapping of Landslide in the study area}

As indicated above, landslides have been successfully and effectively mapped, using geomorphic method and aerial photo interpretation in Jamaica [17-18]. Landslides generally, display key features for example, a back scarp, lobe, body that can be easily recognised on aerial photographs and satellite imagery. In some instances the area of slope failure display distinct 'conical shape'. These areas, even if re-vegetated tends to follow, the underlying shape of the landslides, which may be mapped. 


\subsubsection{Key features mapped and techniques applied}

The scarp/s of landslides even after being vegetate are readily visible. However, the presence of scarp in the landscape by itself does not represent a landslides. If scarps can be mapped and this information is aligns to area/s with a steep gradient, distinct shape typical of a landslide, the presence of debris downslope of the scarp, then probability of a landslide been present increases. Edge enhancement to delineate the scarps area was one of the first step in the process to identifying landslides that was undertaken. This is presented below.

\section{Edge enhancement and Concavit}

As indicated above the scarp is one of the most distinct part of landslides and one of the most readily visible feature of a landslide. Slope curvature is also important in landslide identification. Landslide produce distinct concave surfaces just below the landslide scarp (see Figs 6 and 7). This concave surface, become even more distinct in older landslides where the landslide debris has been eroded away to expose the 'failure plane'. The curvature [20] is a parameter that characterizes surface convexity and concavity.

In order to highlight the scarp and crown, the convolution Laplacian edge-enhancement filter $(3 \times 3)$ was used. Research such as [2], [13]. Demonstrated that thesis is one of the most effective filter in mapping landslide scarp and crowns. The Laplacian filter that approximates the second derivative of terrain also have the benefit of determining slope curvature index [7]. The added value of the Laplacian value is that it can be calculated using one matrix, and as such it is easy to expand the filter window size [12]. The Laplacian's $3 \times 3$ matrix (see Fig. 8) which is a local multiplicative summation of elevations, was used. The positive cells of the Laplacian correspond to convex slopes between. The negative cells correspond to where concave slopes are located below a scarp.

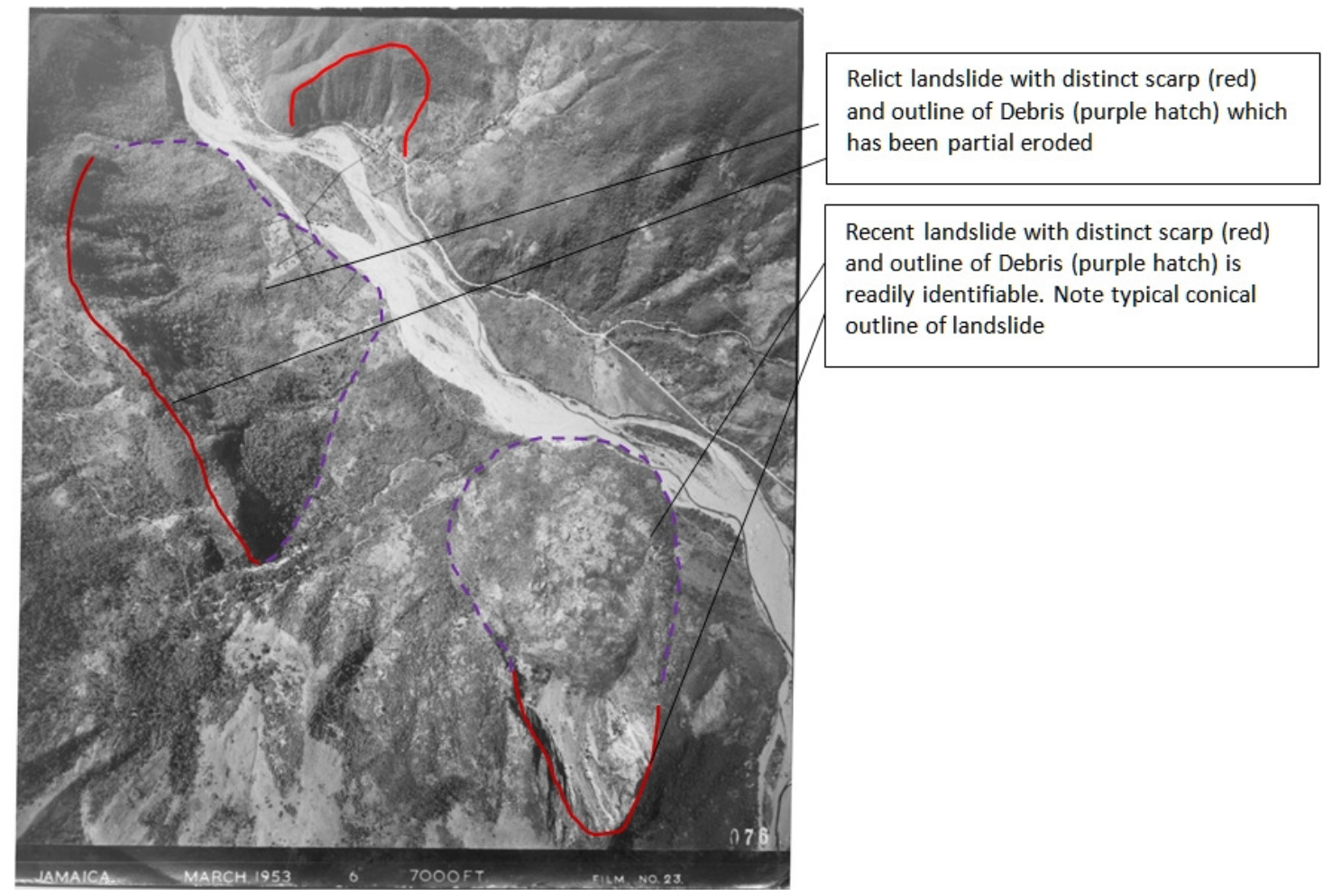

Fig. 7. Distinct features of recent and relict rotational: Key features to be mapped

\begin{tabular}{|r|r|r|}
\hline 0 & -1 & 0 \\
\hline-1 & 4 & -1 \\
\hline 0 & -1 & 0 \\
\hline
\end{tabular}

Fig. 8. A matrix of the $3 \times 3$ filter used for edge enhancement

\subsection{Pattern recognition}

Whilst landslides generally, don't have a distinct spectral signature, in some instances it has an identifiable shape (see Figures 5,6 and 7). Landslides will disturb the existing vegetation when it occurs. This shape it produces will be easily 
recognisable from the surrounding area which can be recognised and mapped from satellite imagery. Even after the vegetation start to recolonize the landslide surface, the pattern created is still likely to show even subtle outline of the underlying landslide. The pattern that may become recognisable may be from a combination of difference in tree heights, less vegetation growth, a more diverse vegetation growth (due to availability of moisture and deeply weather debris), and/or similar vegetation as surrounding area but with stunted growth (due ongoing disturbance due to movements on the slope). However, it has to be recognised that other landscape features (e.g. clear land for agriculture, ponds and small woodland areas etc.), may have similar shape as the landslide feature. Therefore, shape classification cannot be a unique identifier of landslides but can be used in conjunction with other features linked to landslide if mapped (e.g. scarp). Where a distinct shape typical of a landslide coincides with areas in close proximity to a scarp/s with a steep gradient below it and a concave surface, then the probability of landslides increases.

\subsubsection{Image segmentation}

Landslides are of different physical size. As such in order to recognise shapes of different sizes and cope with this variability, the image must be processed at different resolution, Different resolutions characterize different structures in the image [1]. This is process is known as Image segmentation. In order to undertake pattern recognition analysis of the landscape Image segmentation was first undertaken. The use of image segmentation produces homogenous areas by the use of region merging and boundary detection algorithms [see 4-5]. The basic idea of segmentation used is based on [14-15], wavelet transformation idea which produces multiple representations of the IKONOS imagery at different resolutions. The image is passed through a low-pass filter and a band-pass filter at each level. The low pass filter ( $\mathrm{K}$ means algorithm) is used to cluster and smooth the imagery, whereas the band-pass one is used to capture the detail (Bayesian Classifier). The use of wavelet levels helps to capture different details of the landslides inherently found in different structures of the imagery [1]. Once segmentation has been done and the clusters recognised, shape metrices are applied to help to classify the image to land-use [8]. Shape metrics are widely used for landscape classification [16]. One of the most common landscape metric used is FORM [11] and is the one used for this research. As indicated earlier, 'FORM' was used as the preferred method to classify pattern in the landscape. This was due to its success in delineating complex features, for example landslides. Form is calculated from area and perimeter of polygons and is used to represent shape complexity (see Table 2). Using FORM, values are confined between 0 and 1 . Value closer to 0 represent regular shape whereas value closer to approached more complex shape structures. Landslides features are generally complex and the form quite very diverse. However, it is envisage that this will help to differentiate it from feature for example area clear locally for agriculture which may cause some confusion.

Table 2. Output of FORM classification

\begin{tabular}{l|l|l|l}
\hline Code & Name & Calculation scheme & Range \\
\hline FORM $\quad$ Form factor $\quad(4 \pi \times \mathrm{x}) / \mathrm{p} 2, \mathrm{a}:$ area of the polygon, : p: perimeter of the polygon & $(0.1)$
\end{tabular}

\section{Results and Discussion}

The result from edge enhancing, slope curvature, shape index are presented below. Whilst each the methods individually yield useful results, which help to delineate some features of the landslides, individually did not appear to effective discriminate landslides. However, when combined they have proven to highly effective identifying larger landslides but less so for small landslides.

\subsection{Edge enhancing}

Use of The Laplacian's matrix to highlight scarps and concave adjoining surfaces was effective to some extent. Areas delineated by this method will be referred to as 'Scarps' from here on. Most of the 'scarps' and adjoining slopes identified coincide with area of steep gradient, normally over, 30 degrees (see Fig. 9). However, the areas highlighted occurred over significant lengths, following ridges, where it from field mapping experience it would be highly unlikely for a slope failure to occur over such an extended area in this environment. In addition, erosional features and river channels are also being picked up using this method. As expected edge enhancement by itself, was note solely a technique to fully discriminate landslides. 


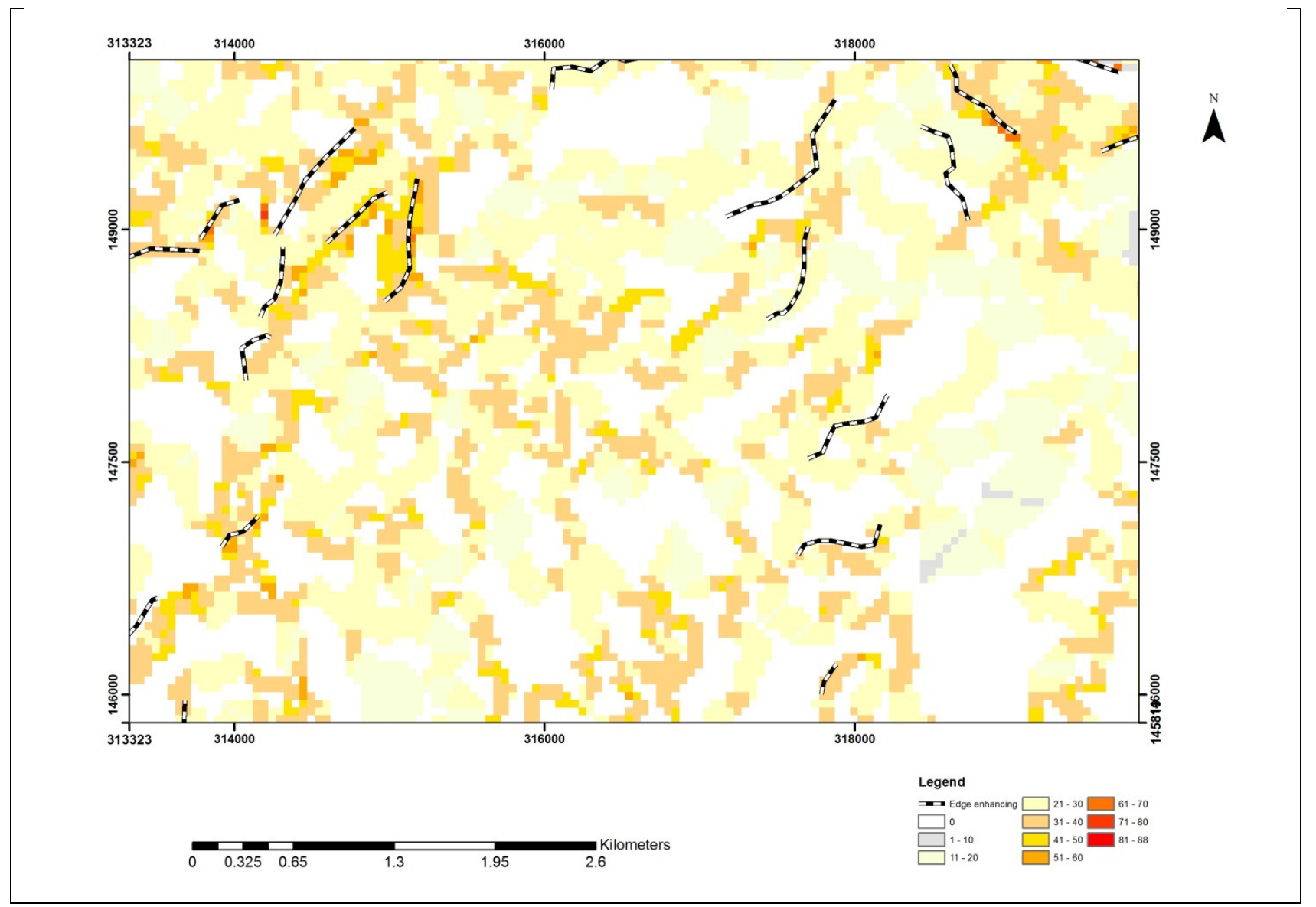

Fig. 9. Area where edges were highlighted adjacent to concave slopes

\subsection{Pattern Analysis}

In order to undertake the initial FORM analysis (see Section 3.2.1 above), an area adjoining area to the west of the study area, 1x1 km was used for 'training'. An existing land-use map with landslides was used as the 'training' dataset. The most common land-use such as cultivated lands, vegetated upland swampy areas, isolated settlement, which may cause confusion with landslides was included. Results of the FORM analysis indicate, that forest and isolated settlement have very low FORM index value and less likely to cause confusion with landslides (see Table 3 below). These features were more likely to regular shape (square, oval, rectangular). However, swamps and small cultivated lands are more likely to be irregular and has complex shape as would a landslides. As such, the range of values obtained from the FORM shape analysis are almost similar (see Table 3). Landslides unlike cultivated land and swamps however, does not have values below 0.41 , which indicate it is less likely to have a regular shape. Most of the from Values for landslides are concentrated above 0.6. Landslide values were also the highest ones calculated. Whilst it recognised that landslides are the most complex shapes, it would be difficult to used FORM as the sole way of mapping landslides. However, these were combined with the scarp, curvature and slope maps to better discriminate areas where all these four variable were present and which could be used inventory landslides. Area clustered based on FORM analysis are defines as landslide blocks for hereon.

Table 3. Results from Form analysis

\begin{tabular}{ll}
\hline Land-use class & FORM Characteristics. \\
\hline Cultivated land & $0.21<$ FORM $<0.79$ \\
Ponds/Swamps & $0.22<$ FORM $<8.0$ \\
Isolated Settlements & $0.06<$ FORM $<0.49$ \\
Forest & $0.12<$ FORM $<0.32$ \\
Landslides & $0.41<$ FORM $<0.84$
\end{tabular}

\subsection{Landslide Scarp, Curvature, Slope and Patterns combination}

A cluster analysis of shapes with FORM values greater than 0.4 were used for further analysis. Whilst some of the typical conical shape were identified clusters produces, the shapes were highly diversed (as the FORM index identified) from 
rounded to elongated (see Fig. 9). The larger the slides, the more complex the space were and the more likely for it to follow the conical form of typical rotational landslides. Small landslies tend to be more circular or square. This discrepancy in the landslide shape at the smaller size may simple be down to pixel resolution of the imagery, with smaller landslides being represented by a few cells, and as such may not be as well defined. However, when shape clusters were overlaid with the edge enhancement/slope curvature information, most of the larger grouping of cells that define landslide blocks were less than 2 metres of areas defined as scarp (see Fig. 10). The combination of these maps also highlighted a number 'scarps' with no clusters of landslide blocks and vice versa. It is interpreted that the areas defined as scarp with no clusters are more likely to be ridge lines, other geomorphic features (e.g. fault lines) in the landscape and/or even possible relict landslides with the body eroded away. The final map used for validation eliminated 'scarps' slopes gradient, curvature and 'landslide block' which did not coincide with each other.

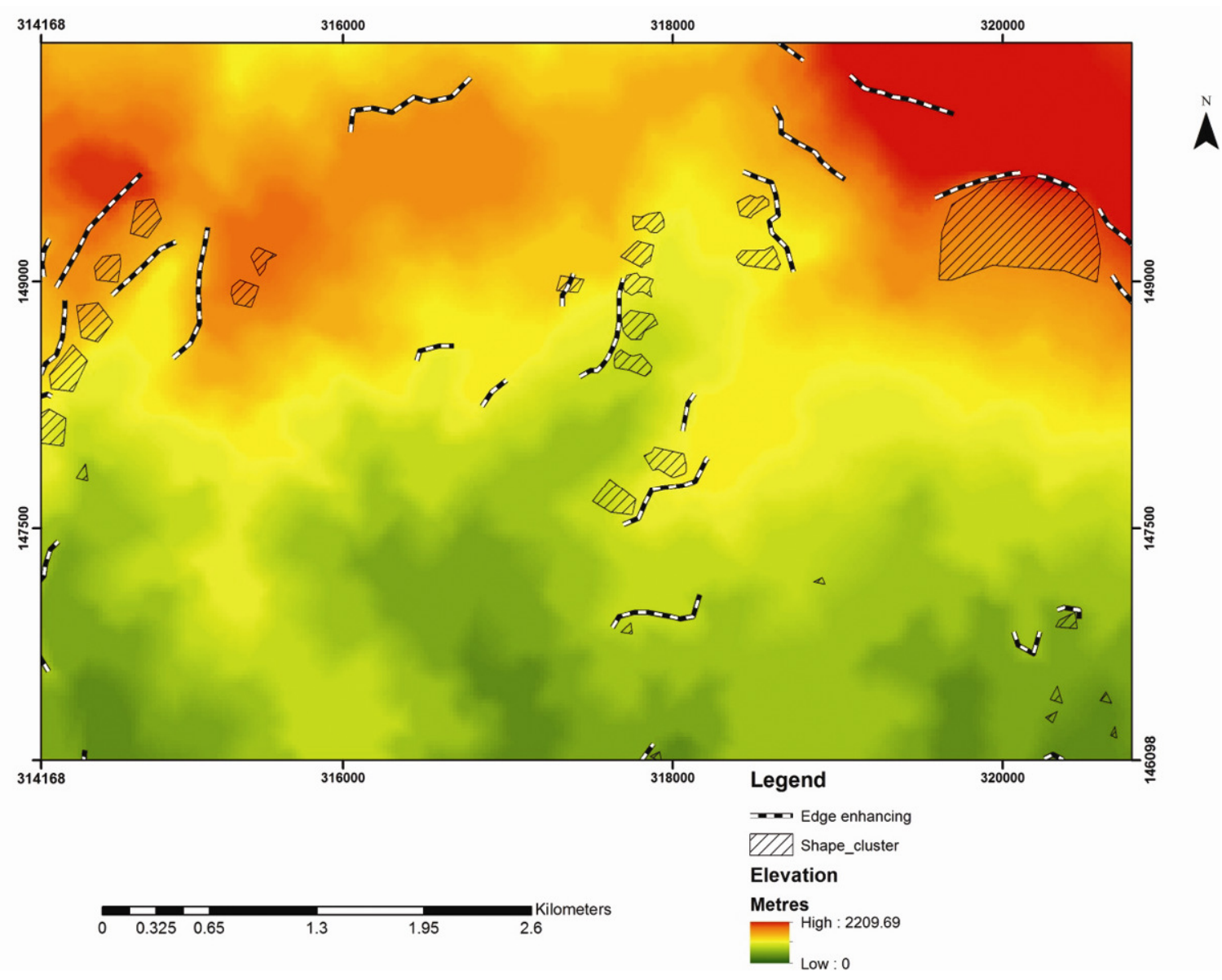

Fig. 10. Combination of Scarp and Shape-FORM information with Elevation data

\section{Validation and conclusions}

The landslide mapping from the Satellite imagery and GIS process was validated against detailed field mapping at a scale of 1:5000 to evaluate the effectiveness of the process. 112 landslides, that were verified in the field were used for comparison with the data derived from remote sensing. Approximately half of these landslides were pre-2000 and the other half, mapped after the heavy rainfalls in 2000. For more recent landslides (post 2000), the modelling proved to be effective, accurately identifying $91 \%$ of the landslide both in terms of the location and extent. For the older landslides (Pre 2000) the mapping was less effective with misclassification using these imagery as high as $24 \%$. Most of the misclassification for both set of landslides were mostly with smaller landslides below 5metres in length. All the landslides over 20m in length (or width) were correctly classified. These larger landslides were predominantly in Limestone rock, where it is more likely their features would have been better preserved. These landslides were mostly rotation slumps which form a more distinct shape and scarp. As such they were more likely to be identified as highly complex shape, with concave surface near and series of scarps. The smaller landslides were in deeply weather volcanic regolith, were more likely to be translational and/or debris flow. These have less well defined scarp and debris is more likely to be rework, spreading over larger area. Features from these landslides are unlikely to be preserved and as such pronounced scarp and a distinctive form may not be evident from satellite imagery analysis and interpretation, particularly for smaller landslides.

Whilst not as successful in mapping all type of landslides, the use of IKONOS imagery has the potential to map large landslides in Limestone terrain (that dominates the island geology) but less so in area underlain by volcanic rock. The technique develop here may prove useful for mapping new landslides quickly and efficiently after landslide disaster, as they 
are much cheaper and quicker to acquire. In the future it is envisage that SAR, RADAR and/or LIDAR to enhance the landslide delineation process, particularly for smaller ones with less pronounced scarps should be utilised and integrated in the process.

\section{Acknowledgements}

This paper was prepared as an outcome of research conducted at the University of Chester, Department of Geography and Development Studies, and as an outcome of statutory research no. 528-0302-0828 Faculty of Geodesy and Land Management, Institute of Geodesy.

\section{References}

[1] Aksoy, S.; G"okhan Akc, ay, H. (unknown ) Multi-resolution Segmentation and Shape Analysis for Remote Sensing Image Classification. Available from: http://www.cs.bilkent.edu.tr/ saksoy/papers/rast05_multires.pdf

[2] Anbalagan, R.; Kumar, R.; Parida, S.; Lakshmanan, K. 2014. GIS Based PostEarthquake LandslideHazard Zonation Mapping of Lachung Basin, Sikkim International Journal of Emerging Technology and Advanced Engineering 4(1): 431. Website: www.ijetae.com (ISSN 2250-2459, ISO 9001:2008 Certified

[3] Barker, D.; McGregor, D. F. M. (Eds). 1995. Environment and Development in the Caribbean: Geographical Perspectives. The Press, UWI, 344p.

[4] Benz, U.C.; Hofmann, P.; Willhauck, G.; Lingenfelder, I.; Hetnen, M. 2004. Multi-resolution, object-oriented fuzzy analysis of remote sensing data for GIS-ready information, ISPRS Journal of Photogrammetry and Remote Sensing 58(3-4): 239-258. http://dx.doi.org/10.1016/j.isprsjprs.2003.10.002

[5] Blaschke, T. 2010. Object based image analysis for remote sensing, ISPRS Journal of Photogrammetry and Remote Sensing 65(1): 2-16. http://dx.doi.org/10.1016/j.isprsjprs.2009.06.004

[6] Bhalai, S. 2010. Landslide Susceptibility of Portland, Jamaica: Assessment and Zonation, Caribbean Journal of Earth Science 41 : $39-54$.

[7] Chen, J. S.; Huertas, A.; Medioni, G. 1987. Fast convolution with Laplacian-of-Gaussian masks, IEEE Transactions on Pattern Analysis and Machine Intelligence PAMI-9, 584-590. http://dx.doi.org/10.1109/TPAMI.1987.4767946

[8] Frohn, R. C. 2006. The use of landscape pattern metrics in remote sensing image Classification, International Journal of Remote Sensing 27(10): 2025-2032. http://dx.doi.org/10.1080/01431160500212229

[9] GEOHAZARDS, 2001. Summer 2003 Geohazards course at UWI, Mona http://www.uwimona.edu.jm/uds/GEOHAZARDS 2001/GEOHAZ2001016.html (Accessed January 9, 2003)

[10] GEOEYE, 2014. DigitalGLOBE. Available from: http://www.geoeye.com/IKONOS.

[11] Iao, L.; Liu, Y. 2012. ISPRS Annals of the Photogrammetry, Remote Sensing and Spatial Information Sciences I-7, 2012, in XXII ISPRS Congress, 25 August - 01 September 2012, Melbourne, Australia

[12] Iwahashi, J.; Pike, R. J. 2007. Automated classification of topography from DEMs by an unsupervised nested-means algorithm and a three-part geometric signature, Geomorphology 86: 409-440. http://dx.doi.org/10.1016/j.geomorph.2006.09.012

[13] Iwahashi, J.; Kamiya, I.; Yamagishi, I. 2012. High-resolution DEMs in the study of rainfall- and earthquake-induced landslides: Use of a variable window size method in digital terrain analysis, Geomorphology 153-154: 29-38. http://dx.doi.org/10.1016/j.geomorph.2012.02.002

[14] Mallat, S. G. 1989. A theory for multiresolution signal decomposition: The wavelet representation, IEEE Transactions on Pattern Analysis and Machine Intelligence 11(7): 674-693. http://dx.doi.org/10.1109/34.192463

[15] Mallat, S. 1996. Wavelets for a vision, Proceedings of the IEEE 84(4): 604-614, April 1996. http://dx.doi.org/10.1109/5.488702

[16] McGarigal, K.; Marks, B. J. 1995. FRAGSTATS: Spatial Pattern Analysis Program for Quantifying Landscape Structure. General Technical Report, PNW-GTR-351, Portland, OR (USDA Forest Service, Pacific Northwest Research Station). Online version (accessed 12 October 2011): http://www.fs.fed.us/pnw/publications/gtrs-prior-1997.shtml.

[17] Miller, S.; Brewer, T.; Harris, N. 2009. Rainfall thresholding and susceptibility assessment of rainfall-induced landslides: application to landslide management in St Thomas, Jamaica, Bulletin of Engineering Geology and the Environment 68(4): 539-550. http://dx.doi.org/10.1007/s10064-009-0232-z

[18] Miller, S.; Harris, N.; Williams, L.; Bhalai, S. 2007. Landslide susceptibility assessment for St. Thomas, Jamaica, using geographical information system and remote sensing methods. In Teeuw, R. Remote Sensing Hazardous Terrain. Geological Society, London, Special Publications, 283: 7791. http://dx.doi.org/10.1144/SP283.7

[19] Robinson, E.; Laughton, D. V.; Ahmad, R. 1997. Burlington and Jupiter landslides, Rio Grande Valley: comparison with Millbank landslide as examples of processes producing natural dams, in R. Ahmad (Ed.). Natural hazards and hazard management in the Greater Caribbean and Latin America: Proceedings of the second Caribbean conference on natural hazards and disasters. Jamaica: UDS, University of the West Indies, 56-61.

[20] Zeyenbergen, L. W.; Thorne, C. R. 1987. Quantitativh analysis of land surface topography, Earth surface processes and landforms 12: 47-56. http://dx.doi.org/10.1002/esp.3290120107 